\title{
Editorial
}

\section{The Independence of Medical Journals and the Deceptive Effects of Open Access}

\author{
Giovanni A. Fava \\ Department of Psychology, University of Bologna, Bologna, Italy
}

\section{Introduction}

When we try to define the role of a specific journal in medical publishing, we generally refer to its impact factor (IF) and position in specific rankings of the Institute for Scientific Information (ISI). These rankings, however, do not differentiate whether a journal exclusively contains review articles (which are more likely to be cited) or also publishes original investigations. Further, ISI categories do not differentiate between clinical and basic science journals, as long as they cover the same discipline. Finally, even within the clinical domain there may be important distinctions: some journals are concerned with a general approach to the discipline (e.g. American Journal of Psychiatry, British Journal of Psychiatry), whereas other publications deal with a subdiscipline (e.g. Journal of Affective Disorders, Schizophrenia Bulletin) or a specific approach (Biological Psychiatry, Psychotherapy and Psychosomatics).

An issue that is seldom addressed is the financial independence of a journal. There may be substantial commercial influences on the content of medical journals [1]. There is a very wide range of situations that may be encountered, which are complicated by the fact that the majority of journals neither have policies on their editors' conflicts of interest [1] nor require disclosure statements regarding these conflicts, contrary to what the most influential editors' associations recommend [2]. On the one hand, the highest degree of financial inde-

\section{KARGER}

E-Mail karger@karger.com

www.karger.com/pps pendence is found in the purely subscription-based, advertising-free journal, with an editor who has no conflict of interest, as is the case with our journal. This type of journal may charge authors a fee when the number of pages exceeds that allotted, or in the presence of special features such as color photographs. On the other hand, the least financial independence occurs with journals that are financed (completely or in part) by private companies or that require the payment of a fee for publishing an article, as occurs in open-access journals. A variant of this type of journal is the subscription-based publication, which systematically charges a fee for each published page. Between the subscription-based journals and the directly financed/open-access publications there are journals that include advertising and/or are owned by medical organizations. Financial dependence may be subtle here and mediated by the medical organization. Articles in medical journals that criticize a drug or a certain establishment can result in a substantial loss of advertising revenue, as many examples indicate [1]. Glassman et al. [3] investigated whether revenues generated from pharmaceutical advertisements in medical journals create potential conflicts of interest for the nonprofit physician organizations that own those journals. They found that the financial conflicts of interest were substantial, and some prestigious medical organizations such as those underlying the JAMA and the New England Journal of Medicine could be viewed as beholden to the drug industry. 


\section{The Commercial Nature of Open-Access Journals}

Open-access journals do not limit the readership by subscription. The progressive demand for free availability of scientific resources on the Internet follows the principle that the knowledge conveyed in these publications is a public good and should therefore be spread as much as possible [4]. In the medical field there has been a movement toward centralizing medical free-access information (PubMed Central). The whole emphasis in this apparent quest for the common good is on fruition of the scientific literature. However, access is only open to readers and not to potential contributors, since the latter have to pay for publishing. This means limiting the opportunity to publish to authors whose work is supported by grants, to those who are loaded with conflicts of interest and have private companies behind them, and/or to those who work in institutions that may pick up the bill. In the past decade, the issue of commercial interests, and particularly of conflict of interest, in open-access journals was seldom raised [5]. But the commercial nature of open-access journals is now more and more obvious when we witness the birth of new such journals that are not necessarily prompted by intellectual stimuli, and when in our E-mail inboxes we receive pressing requests for contributions daily. What they want is simply our money. And the right of investigators to have free access to publishing is seriously challenged.

\section{Censorship and Leitkultur}

Corporate interests often result in self-selected academic oligarchies (special interest groups) that influence clinical and scientific information [6]. Members of special interest groups, by virtue of their financial power and close ties with other members of the group, have the task of systematically preventing the dissemination of data which may be in conflict with their interests. The first target is to undermine the critical individual judgment of physicians, which requires massive doses of censorship. Censorship may take different forms: direct suppression of information by special interest groups who act as editors and reviewers or make choices in scientific programs; careful selection of the literature in a biased direction and manipulated interpretation of clinical trials (including those supported by public sources); self-censorship (when an investigator refrains from raising questions and criticism for fear of retaliation) [6]. The notion of a special interest group also includes researchers who may not re- ceive direct financial incentives for their participation but may benefit from power and visibility which they would not otherwise enjoy (which explains how mediocre scientists may get important positions). Other instrumental methods are: the substitution of critical reviews for metaanalyses whose data could be easily manipulated [7]; an emphasis on clinical guidelines by experts with major conflicts of interest [8]; full control of medical societies, their journals and their meetings [3], and keeping medical literature as far away as possible from the clinical problems of daily practice. Occasional articles taking anti-pharma positions may serve the purpose of claiming independence and of masking the fact that special interest groups are using evidence-based medicine as a sort of 'Leitkultur', a German term that connotes the cultural superiority of a culture, with policies of compulsory cultural assimilation [9]. Free access, then, becomes free access to what one is allowed to see by production restrictions. The clinician who wonders about certain treatment protocols is intimidated by this Leitkultur of meta-analyses and treatment guidelines and thinks that he/she is doing something wrong by not being able to achieve what the propaganda promotes.

\section{The Intellectual Capital of Medicine}

Halstead R. Holman, in a paper published in Hospital Practice in 1976 [10] which anticipated some developments in health care of the following four decades, observed that 'the medical establishment is not primarily engaged in the disinterested pursuit of knowledge into medical practice; rather in significant part it is engaged in special interest advocacy, pursuing and preserving social power. The concept of excellence is a component of the ideological justification of that role' ([10], p. 11). Holman identified a decline in intellectual freedom as a major source of the 'excellence deception', which perpetuates prevailing practices, deflects criticism and insulates the profession from alternative views and social relations that would illuminate and improve health care. Medical knowledge instead is the cumulative experience of human history as 'a legacy from those who have gone before to those who live today' and as 'a social possession' ([10], p. 21).

The intellectual capital of medicine is the creativity linking research and clinical practice. The development of models that may entail better explanations of clinical phenomena and of innovations in clinical practice strictly depends on this interaction and on a pluralism of view- 
points [11]. However, such interaction is increasingly threatened. For instance, in many medical journals the section concerned with correspondence has often been trimmed in recent years, whereas it used to report important reactions by clinicians to what had been published. Pluralism is threatened by the Leitkultur of evidencebased medicine [9] and open-access journals.

Our journal pursues the 'clinical factor', the degree and extent to which a journal provides information to the clinician that may improve his/her practice [12]. Richard Balon [13-15], in a series of annual papers, has tried to select investigations published in psychiatric journals which he perceived as having a high clinical factor. One is impressed by the amount of important research that has not been funded. Truly innovative research is unlikely to be funded, also by public sources. Further, the reporting of side effects which may occur serendipitously is also unlikely to be funded.

\section{The Role of Medical Journals}

The intellectual capital of medicine, if the proper methodological requirements are met, needs to find free expression in publishing. Medical journals should be differentiated by their mission and characteristics and not simply classified according to their ranking in ISI categories. Their financial support is important in determining their intellectual autonomy. Readers, on the other hand, should become more sophisticated in the appraisal of medical literature and privilege critical or systematic reviews by authors who are free of substantial conflicts of interest, as described in detail elsewhere [6]. Innovations are unlikely to pass through medical journals that select large, major trials and a general focus, and may be more likely to occur in journals with a more targeted approach and a high degree of financial independence. It is important to offer an opportunity to creative investigators, particularly in their initial phase, to communicate their insights and to trigger changes in paradigms. Brainwashed by evidence-based medicine, many investigators aim only at large randomized controlled trials, whereas other types of design may provide important information that is missing in current clinical medicine [16].

Evidence-based medicine has certainly provided an important historical contribution to the scientific development of medical literature in the past two decades. Time has come, however, to become aware of its considerable limitations, overall reductionism, insufficient con- sideration of problems related to financial conflicts of interest, disregard of the patient-physician relationship (including patients' preferences) and lack of integration with clinical judgment. Alternative ways of assessing evidence should be explored. For instance, in discussing treatment options in depression, the choice of the main evidencebased treatment ingredients (pharmacotherapy and psychotherapy) can be placed in the context of clinical judgment [17], outlining the advantages and disadvantages that each treatment selection has.

\section{Creating Alternatives to Open-Access Journals}

The open-access movement has triggered some positive changes. In many subscription-based journals, including ours, editors select articles to be freely accessible, in virtue of their particular value and clinical implications. Further, authors who wish their article to be freely accessed and have the financial resources to do it may elect to do so. Finally, in many journals, contents become freely available 1 year after publication. The border that separates free access from other journals has thus become more blurred. Certainly more can be done. For instance, the cost of getting access to individual articles is still outrageously high. If 99 US cents is the cost of downloading a song, one may wonder why a similar amount of money does not suffice for scientific articles. Readers should have a more active role in supporting the intellectual capital of medicine and in assessing financial independence (either of the papers or of the journals that host them). To a physician, getting independent information is valuable and may have a reasonable price. For instance, a single critical review article where 1 or 2 experts who have no financial ties analyze the literature, drawing from their personal clinical experience and the methodological insights gained by their own research, is worth more than 100 systematic reviews, often ghostwritten, characterized by intellectual mediocrity and unfamiliarity with the clinical process, and with a plea for further research as their main conclusion [9]. In due course, as often happens with innovations, it is becoming clear that authors should not subsidize medical publishing and that the open-access medical journal business is totally out of control. A better balance between free access to medical publishing and availability of scientific resources in an era of information overload [5] can be achieved, but the open-access formula appears to be inadequate in this respect. 


\section{Our Journal's Mission}

We will continue to depend on our readers and subscribers and make full use of the independence that this choice allows [18]. We aim to provide a forum for innovative thinking at the interface between behavioral and medical sciences and to host contributions that special interest groups would not allow to appear in other journals, including critical commentaries on articles published elsewhere as well as negative trials. We look for critical reviews, whether systematic or not, that may shed some light on important clinical issues. Meta-analyses should be carried out with sufficiently homogeneous patient groups [16]. We pursue the clinical factor [12-15] in the limited number of articles that we can publish.

Psychotherapy research is a major area of interest. Interestingly in this respect, an editorial in Nature [19] judged studies on psychological treatments 'scandalously under-supported', despite their 'potential to make a substantive difference to patients'. It concluded that 'many funding agencies around the world are too keen solely to support mechanistic investigations with potential longterm payoffs, and too unwilling to appreciate that part of their portfolio should be oriented towards identifying immediately effective psychological interventions' ([19], p. 474). Psychotherapy research is not only 'scandalously under-supported': it is also scandalously boycotted by many psychiatric journals, particularly when it is not presented as complementary to medication in a politically correct formulation but as an alternative to drug treatment. We encourage publications on new assessment and treatment strategies in mood and anxiety disorders, including the detection of iatrogenic effects and the role of previous treatments $[16,20]$. Psychosomatic medicine and clinimetrics are other major areas of interest of the journal.

\section{Appendix}

Psychotherapy and Psychosomatics has again increased its IF in 2012. Its new IF of 7.23 places the journal as 5 th in the Psychology ranking and 8th in the Psychiatry ranking. In the Science Citation Index Psychology ranking, the 4 journals preceding Psychotherapy and Psychosomatics are exclusively dedicated to review articles. This indicates that Psychotherapy and Psychosomatics is the top journal for original investigations in psychology.

Such achievement is the result of several converging efforts. The following experts have supplemented the editorial board by reviewing the manuscripts submitted to Psychotherapy and Psychosomatics in 2013 and are gratefully acknowledged. Both exter-

nal referees and editorial board members have disclosed potential conflicts of interests. The Editor-in-Chief and the Assistant Editors have no conflicts of interest to declare for 2013. We should acknowledge here: the perfect synchrony between Karger's editorial office and the invaluable assistant editors Chiara Ruini and Elena Tomba; the work of the editorial board and statistical consultants; the help by many external reviewers (listed below), who dedicated their time and effort to assess and improve the quality of submitted manuscripts; the skills of Carlotta Belaise, who prepared the press releases of the published articles; and the support from our authors and readers.

E. Albieri (Bologna, Italy)

F. Amianto (Torino, Italy)

B. Arnetz (Detroit, Mich., USA)

D. Barnes (San Francisco, Calif., USA)

A. Bartak (Amsterdam, The Netherlands)

N. Batelaan (Amsterdam, The Netherlands)

C. Belaise (Bologna, Italy)

T. Berger (Bern, Switzerland)

K. Boylan (Hamilton, Ont., Canada)

E.L. Brakemeier (Berlin, Germany)

S. Brand (Basel, Switzerland)

V. Brandes (Salzburg, Austria)

A. Buske-Kirschbaum (Dresden, Germany)

V. Cardi (London, UK)

C. Carney (Toronto, Ont., Canada)

H. Chapman (Columbus, Ohio, USA)

M. Chiesa (Richmond, UK)

D. Clarke (Melbourne, Vic., Australia)
C. Colagiuri (Sydney, N.S.W., Australia)

A. Compare (Bergamo, Italy)

F. Cosci (Firenze, Italy)

C. Csillag (Hillerød, Denmark)

C. Cusin (Boston, Mass., USA)

K. Dalrymple (Providence, R.I., USA)

J. Dekker (Amsterdam, The Netherlands)

L. Del Piccolo (Verona, Italy)

R. Delle Chiaie (Roma, Italy)

F. Facchinetti (Modena, Italy)

P. Fink (Aarhus, Denmark)

L. Fjorback (Aarhus, Denmark)

J. García-Campayo (Zaragoza, Spain)

J. Gensichen (Jena, Germany)

G. Grande (Leipzig, Germany)

L. Grassi (Ferrara, Italy)

S. Grimm (Berlin, Germany)

J. Guidi (Bologna, Italy) 
M. Hartmann (Heidelberg, Germany)

G. Hasler (Bern, Switzerland)

T. Heidenreich (Esslingen, Germany)

G. Hervas (Madrid, Spain)

A. Huber (Modena, Italy)

K. Huijbregts (Utrecht, The Netherlands)

R.B. Jarrett (Dallas, Tex., USA)

R. Johansson (Linköping, Sweden)

G. Keitner (Providence, R.I., USA)

Z. Kozinszky (Karlskrona, Sweden)

R. Kupka (Amsterdam, The Netherlands)

P. Leombruni (Torino, Italy)

M. Linden (Teltow/Berlin, Germany)

G. Maina (Torino, Italy)

K. Manassis (Toronto, Ont., Canada)

E. Melchiorri (Bologna, Italy)

B. Metternich (Freiburg, Germany)

J. Moncrieff (London, UK)

P. Monteleone (Napoli, Italy)

H. Mörgeli (Zurich, Switzerland)

C. Muhtz (Hamburg, Germany)

U. Nater (Marburg, Germany)

B. Netterstrøm (Copenhagen, Denmark)

A. Nierenberg (Boston, Mass., USA)

E. Offidani (Bologna, Italy)

J.S. Ogrodniczuk (Vancouver, B.C., Canada)

T. Oka (Fukuoka, Japan)

Y. Osher (Beer Sheva, Israel)

S.D. Ostergaard (Boston, Mass., USA)

S.B. Patten (Calgary, Alta., Canada)

R. Penadés (Barcelona, Spain)

K.A. Phillips (Providence, R.I., USA)

A. Picardi (Roma, Italy)

A. Preti (Cagliari, Italy)

S. Priebe (London, UK)
G. Ranjith (London, UK)

V. Ricca (Firenze, Italy)

K. Rickels (Philadelphia, Pa., USA)

A.K. Risch (Jena, Germany)

R. Roncuzzi (Bologna, Italy)

M. Rosselli (Firenze, Italy)

J. Roth (Dresden, Germany)

J.K. Salminen (Turku, Finland)

R. Schaefert (Heidelberg, Germany)

F. Schifano (Hatfield, UK)

D. Schiffer (Torino, Italy)

S. Schneider (Bochum, Germany)

L. Sharpe (Sydney, N.S.W., Australia)

L. Sirri (Bologna, Italy)

N. Sonino (Padova, Italy)

L. Staccini (Bologna, Italy)

J. Stone (Edinburgh, UK)

L. Swanson (Ann Arbor, Mich., USA)

L. Sylvia (Boston, Mass., USA)

L. Tarsitani (Roma, Italy)

D. Taylor (Denton, Tex., USA)

G.J. Taylor (Toronto, Ont., Canada)

L. Tecuta (Bologna, Italy)

J. Treasure (London, UK)

E. Tossani (Bologna, Italy)

C.M. van der Feltz-Cornelis (Utrecht, The Netherlands)

R. van der Lem (Leiden, The Netherlands)

B. Van Houdenhove (Leuven, Belgium)

F. Veglio (Torino, Italy)

F. Vescovelli (Bologna, Italy)

H. Walach (Frankfurt, Germany)

P. White (London, UK)

A.M. Wood (Manchester, UK)

J.B. Zantvoord (Amsterdam, The Netherlands).

\section{References}

$>1$ Lexchin J, Light DW: Commercial influence and the content in medical journals. BMJ 2006;332:1444-1447.

-2 Davis RM, Müllner M: Editorial independence of medical journals owned by professional associations: a survey of editors. Sci Eng Ethics 2002;8:513-528.

$>3$ Glassman PA, Hunter-Hayer J, Nakamura T: Pharmacological advertising revenue and physician organizations: how much is too much? West J Med 1999;171:234-238.

4 Willinsky J: The Access Principle: The Case of Open Access to Research and Scholarship. Cambridge, MIT Press, 2006.

$>5$ Fava GA, Guidi J: Information overload, the patient and the clinician. Psychother Psychosom 2007;76:1-3.

6 Fava GA: Unmasking special interest groups: the key to addressing conflict of interest in medicine. Psychother Psychosom 2010;79: 203-207.
7 Fava GA: Meta-analyses and conflict of interest. CNS Drugs 2012;26:93-96.

$\checkmark 8$ Choudhry NK, Stelfox HT, Detsky AS: Relationships between authors of clinical practice guidelines and the pharmaceutical industry. JAMA 2002;287:612-617.

$>9$ Fava GA: Clinical judgment in psychiatry: requiem or reveille? Nord J Psychiatry 2013;67: $1-10$.

10 Holman HR: The 'excellence' deception in medicine. Hosp Pract 1976;11:11-21.

$>_{1}$ Sniderman AD, Furberg CD: Pluralism of viewpoints as the antidote to intellectual conflict of interest in guidelines. J Clin Epidemiol 2012;65:705-707.

12 Fava GA: The clinical factor. Psychother Psychosom 2011;80:1-3.

13 Balon R: Clinical factor 2010. Psychother Psychosom 2011;80:195-198.
14 Balon R: Clinical factor 2011. Psychother Psychosom 2012;81:199-205.

15 Balon R: Clinical factor 2012. Psychother Psychosom 2013;82:204-212.

16 Fava GA, Tomba E, Tossani E: Innovative trends in the design of therapeutic trials in psychopharmacology and psychotherapy. Progr Neuropsychopharmacol Biol Psychiatry 2013;40:306-311.

$\checkmark 17$ Tomba E, Fava GA: Treatment selection in depression: the role of clinical judgment. Psychiat Clin N Am 2012;35:87-98.

18 Karger T, Karger S: Some thoughts from your publisher. Psychother Psychosom 2002;71: 63.

19 Therapy deficit: studies to enhance psychological treatments are scandalously undersupported (editorial). Nature 2012;489:473474.

20 Tomba E: Nowhere patients. Psychother Psychosom 2012;81:69-72. 